\title{
Interface
}

\section{REFLEXÕES SOBRE A EDUCAÇÃO ESPECIAL NO MUNICÍPIO DO CRATO}

\author{
Vanessa Cinthya Bandeira Garcia (1)
}

\begin{abstract}
Resumo
Muito tem se falado a respeito dos direitos e necessidades das pessoas com necessidades educacionais especiais. Porém, percebe-se que a pessoa portadora de deficiência tem encontrado grandes obstáculos para a sua aceitação e participação na sociedade. É necessário refletir sobre a realidade da inclusão das pessoas com necessidades educacionais especiais como um todo, bem como o que ainda está impedindo ou dificultando a presença ou permanência destes sujeitos no meio escolar regular. O presente estudo tem como objetivo refletir sobre a realidade da educação especial no município do Crato-CE. Os professores de escolas onde há educação básica inclusiva, participaram da pesquisa, através de entrevistas individuais. Os resultados mostraram que ainda permanece o preconceito com relação a inclusão, por desconhecimento acerca da realidade desses alunos. Também observou-se que uma maior preparação do professorado quanto a aspectos metodológicos do trabalho com Portadores de Necessidades Especiais, certamente contribuiria para uma melhoria do processo ensino-aprendizagem destes alunos.
\end{abstract}

Palavras-chave: Direito. Necessidades Educacionais Especiais. Inclusão.

A Educação Especial é uma forma direcionada de atender aos alunos com alguma necessidade educativa especial. Seja por deficiência mental, deficiência visual, deficiência auditiva, deficiência física, deficiências múltiplas (duas ou mais deficiências), altas habilidades (superdotados), comportamentos típicos de pessoas com síndrome e quadros neuropsicológicos ou psiquiátricos.

Para efeito deste estudo, levaremos em consideração a clientela com maior demanda, no ensino regular (Necessidades especiais por deficiência mental e deficiência auditiva).

Em geral, as pessoas com Necessidades Educativas Especiais por Deficiência Mental são indivíduos que, em geral, apresentam características de desenvolvimento intelectual 
abaixo da média, possuem limitações associadas a duas ou mais áreas da conduta adaptativa ou, na capacidade em responder adequadamente nos seguintes aspectos: comunicação, cuidados pessoais, habilidades sociais, desempenho na família e na comunidade, saúde e segurança, desempenho escolar, lazer e trabalho (SEDUC: 1998, p.99).

Normalmente o diagnóstico do aluno é feito por um Psicólogo, quando são identificadas características e intensidade de algumas manifestações de comportamento tais como: dificuldade de compreensão, aprendizagem muito lenta, vocabulário limitado, dificuldade de concentração e atenção, memória falha, dificuldade de conviver com os colegas.

As pessoas com Necessidades Educativas Especiais por Deficiência Auditiva (D.A.) caracterizam-se pela perda total ou parcial, congênita ou adquirida, da capacidade de compreender a fala através do ouvido.

O grau de surdez é mensurado através da capacidade de ouvir em determinados decibéis (unidade adimensional usada para exprimir a razão de duas potências, igual a 1/10 do bel, correspondendo, pois, a 10 vezes o logaritmo decimal da razão das potências [símb.: $d B]$ ).

Este tipo de deficiência se manifesta como: surdez leve, moderada até 70 decibéis que impede o individuo de se expressar oralmente bem como se percebe a voz humana com ou sem a utilização de um aparelho auditivo. Surdez severa, profunda: perda auditiva de 70 decibéis que impede o individuo de entender, com ou sem a utilização do aparelho auditivo, a voz humana, bem como de adquirir naturalmente o código da língua oral. Os alunos com D.A. necessitam de métodos, recursos didáticos e equipamentos especiais para correção e/ou desenvolvimento da fala e da linguagem (SEDUC, 1998, p.99).

Em geral os portadores de D.A. possuem uma grande dificuldade de comunicação, já que no meio em que vivem é mais utilizada a fala. Por esta razão, encontram muita dificuldade de relacionamento com as pessoas em casa, na escola, na rua, gerando o afastamento e isolamento dos mesmos.

A Língua Brasileira de Sinais - LIBRAS, que consiste na codificação de letras, números e expressões através de gestos realizados, basicamente pelas mãos ou com a leitura labial já é uma realidade no Brasil, demonstrando um avanço no que se refere à inclusão dos surdos na sociedade. Recentemente foi determinado pelo Ministro da Educação que a LIBRAS será disciplina obrigatória em cursos de licenciatura. As universidades terão dez anos para oferecer o ensino de LIBRAS em todos os cursos de formação de professores. Assim a comunicação e aprendizagem de e com portadores de deficiência auditiva estará mais próxima do ideal. 
A Educação Especial visa garantir o ingresso e permanência dos alunos com necessidades especiais e educacionais no ensino regular, formando cidadãos conscientes e participativos, capazes de lutares por uma sociedade mais justa, seja no campo de trabalho, esporte, artes, cultura, dentre outros.

A visão mais tradicional dos portadores de necessidades especiais como "coitadinhos" reforça no senso comum uma idéia de que há uma diferença absoluta; que existem quase que duas espécies de seres humanos, sendo que uma delas é de "segunda categoria" (a dos portadores de deficiência). É importante discutir melhor tal visão, de forma a se iniciar uma desconstrução de determinados mitos, que limitam e impedem que se expressem as suas capacidades.

A década de 90 representou a ampliação efetiva de oportunidades educacionais de qualidade para as pessoas com necessidades educativas especiais, como responsabilidade da escola pública. Tomando como referência a Constituição de 1988, que registrou o direito público subjetivo à educação de todos os brasileiros, inclusive os portadores de deficiência, preferencialmente junto à rede regular de ensino, a questão das políticas públicas tornou-se mais presente em diferentes espaços da legislação educacional. As novas constituições estaduais e as leis orgânicas municipais reproduziram ou ampliaram as referências à educação especial (GLAT, 1997).

Em 1989, a Lei 7.853, que dispõe sobre o apoio às pessoas portadoras de deficiência, reafirmou a obrigatoriedade da oferta da educação especial em estabelecimentos públicos de ensino; a "matrícula compulsória em cursos regulares de estabelecimentos públicos e particulares de pessoas portadoras de deficiência capazes de se integrarem no sistema regular de ensino"; e definiu como crime o ato de "recusar, suspender, procrastinar, cancelar ou fazer cessar, sem justa causa, a inscrição de alunos em estabelecimento de ensino de qualquer curso ou grau, público ou privado, por motivos derivados da deficiência que porta". O decreto que regulamenta a Lei, publicado dez anos depois (Decreto No. 3.298, de 20.12.99), explicita que os serviços de educação especial serão ofertados nas escolas públicas ou privadas "mediante programas de apoio para o aluno que está integrado no sistema regular de ensino, ou em escolas especializadas exclusivamente quando a educação das escolas comuns não puder satisfazer as necessidades educativas ou sociais do aluno ou quando necessário ao bem estar do educando" .

Nas várias reformas educacionais ocorridas no país nos últimos anos, com destaque para a nova Lei de Diretrizes e Bases da Educação Nacional, de 1996, o tema das necessidades educativas especiais esteve presente, com a referência comum da responsabilidade do poder 
público e da matrícula preferencial na rede regular de ensino, com os apoios especializados necessários. A referência ao papel central da escola comum na educação dos alunos que apresentam necessidades educacionais especiais foi também assumida pela adesão do Governo Brasileiro à Declaração de Salamanca, de 1994.

Registrou-se ainda nesta década, a expansão continuada do ensino fundamental, com a taxa de matrículas atingindo mais de $90 \%$ das crianças a partir de 7 anos. Foi expressivo o crescimento da educação infantil, principalmente na primeira metade dos anos 90; também relevante o "status" de nível de ensino a ela atribuído (GLAT, 1997).

Notadamente a partir do início deste século, estudos vêm demonstrando que as diferenças individuais, quer sob o ponto de vista de desenvolvimento cognitivo, quer sob o ponto de vista físico ou sensorial, não constituem uma fatalidade irremovível, nem desabilitam as pessoas para a plenitude de suas realizações pessoais e sociais. Cada indivíduo, com personalidade própria e padrões específicos de desempenho, é dotado de um potencial que, convenientemente orientado, pode permitir, a sua auto-realização.

Dessa forma, o que se está defendendo é a construção de uma sociedade inclusiva que estabeleça um compromisso com as minorias, dentre as quais se inserem os alunos que apresentam necessidades educacionais especiais. Segundo Werneck (1977) a inclusão vem quebrar barreiras cristalizadas em torno de estigmatizados.

O movimento pela sociedade inclusiva é internacional. O Brasil está engajado nele, uma vez que, cerca de 15 milhões de brasileiros apresentam algum grau de deficiência. Eles aguardam a oportunidade de participar plenamente da vida em sociedade, como lhes assegura a nossa Constituição Federal.

Sem dúvida, a democracia, como um fim, constitui um processo de solução e de encaminhamento de propostas e programas, de adoção de regras aceitas pela maioria, mas com pleno respeito às minorias. É um processo que deve, cada vez mais, ampliar o acesso a direitos e garantir a plena participação de todos, utilizando regras claras e aplicáveis a todos, independentemente de raça, cor, sexo, religião e origem social.

A nova proposta de educação inclusiva foi deflagrada pela Declaração de Salamanca, a qual proclamou, entre outros princípios, o direito de todos à educação, independentemente das diferenças individuais. Esta declaração teve como referência a Conferência Mundial sobre a Educação para Todos.

O que passamos a chamar de Educação Inclusiva, propõe que todas as pessoas com necessidades educacionais especiais sejam matriculadas em escolas regulares, baseando-se no princípio de educação para todos. Entretanto, é preciso cautela no sentido de, não admitir uma 
falsa idéia de escola democrática. A escola será mais democrática à medida que acolher, educar, e ensinar a todos, ao tempo em que respeitar as diferenças individuais, estimulando em especial, o desenvolvimento das capacidades do aluno.

Frente a esse novo paradigma educativo, a escola deve ser definida como uma instituição social que tem por obrigação atender a todas as crianças, sem exceção. A escola deve ser aberta, pluralista, verdadeiramente democrática e de qualidade.

Como afirma Rego (1995, p.56):

A escola deve ser um espaço para as transformações, as diferenças, o erro, as contradições, a colaboração mútua e a criatividade. Dessa forma, precisamos de uma escola que não tenha medo de arriscar, que tenha muita coragem para criar e questionar o que está estabelecido, em busca de rumos inovadores, necessários à inclusão.

Segundo Mantoan (1977, p.48): “Cabe a escola encontrar respostas educativas para as necessidades de seus alunos e exigir dela uma transformação”. A inclusão na escola seria, então, o processo pelo qual a própria escola adapta-se, transforma-se para poder inserir em suas classes regulares crianças e jovens com deficiência que estão em busca de seu pleno desenvolvimento de cidadania e exercício da cidadania.

Tanto os alunos ditos normais como os deficientes devem ter a oportunidade de conviver com a riqueza que a diferença representa e, com isso, fortalecer o sentimento de solidariedade. Neste processo, o importante é a necessidade da formação da consciência crítica dos profissionais da educação quanto à sua responsabilidade pela aprendizagem de seus alunos.

Não se pode, igualmente, deixar de registrar que este novo paradigma educativo não permitirá que a Educação Especial seja entendida como um sistema paralelo ou subsistema no contexto do sistema geral da educação. Para este novo tempo é imprescindível a ação conjunta da Educação Regular com a Educação Especial. Afinal, o aluno que apresenta necessidades educacionais especiais, além de ser visto à luz das suas deficiências, deverá ser visto, agora, como ser global e único. 


\section{A Educação Especial no Brasil: Aspectos Históricos}

No Brasil, o atendimento às pessoas com necessidades educativas especiais ocorreu com a criação do Instituto Benjamin Constant e Instituto Nacional de Educação de Surdos no Rio de Janeiro, no final do século XIX (SEDUC, 1998).

Durante muito tempo, os deficientes foram considerados seres distintos e bastante discriminados. À medida que o direito do homem à igualdade e à cidadania tomou um espaço na sociedade, os grupos sociais sentiram-se mais encorajados a lutar por acesso e melhores condições de ensino e assim, a história da Educação Especial começou a tomar um novo rumo. A luta pela igualdade, conquista e direitos das pessoas com necessidades especiais e educacionais tem ocupado importantes espaços nos encontros, convenções e congressos que se realizam em todo o país.

Não poderíamos falar sobre inclusão de pessoas com necessidades especiais sem antes citar a APAE (Associação de Pais e Amigos dos Excepcionais); de sua importância para o deficiente, pois foi através dela que puderam ter uma vida mais digna, tendo acesso a lugares que antes eram desconhecidos para eles (escola, cidade...). Foi também através da APAE que a sua inserção na família, na comunidade e na sociedade de maneira mais plena, tornou-se possível.

No Brasil, a primeira iniciativa de congregar pais de pessoas portadoras de necessidades especiais e, outras pessoas interessadas em apoiá-los, ocorreu no estado do Rio de Janeiro, por iniciativa de uma mãe de criança portadora de Síndrome de Dawn, Beatrice Bemis, membro do corpo diplomático norte-americano. Tendo participado da fundação de mais de duzentas e cinqüenta associações de pais de pessoas com deficiência(s) nos Estados Unidos, a $\mathrm{Sr}^{\mathrm{a}}$ Beatrice Bemis admirava-se por não existir, no Brasil, nenhum trabalho dessa natureza (APAE - Rio, 1991).

Em julho de 1954, realizou-se na Embaixada Americana o primeiro encontro entre pais, mestres e técnicos, interessados na questão das pessoas com deficiência, exibindo um filme sobre crianças que apresentavam deficiência mental. A partir deste momento iniciou-se uma série de reuniões com o intuito de criar uma entidade para dar assistência a pessoas que necessitasse de uma educação especial (GLAT, 1998).

No dia 11 de dezembro de 1954, foi fundada a primeira APAE do Brasil, em sessão realizada na Associação Brasileira de Imprensa na cidade do Rio de Janeiro, destinada a "promover o bem-estar dos excepcionais". 
Em 4 de abril de 1961, doze famílias de crianças portadoras de síndrome de Down após varias reuniões decidem, na cidade de São Paulo, buscar recursos para a construção de uma sede própria, e promoveram a I Feira da Bondade. Na ocasião a líder do movimento Jô Clemente e o então prefeito de São Paulo, brigadeiro Faria Lima, descerram a faixa de abertura do evento e durante a solenidade, o prefeito se comprometeu a ceder um terreno, na Vila Clementino, à entidade. É onde está até os dias de hoje.

Em maio de 1961, por iniciativa de pais e profissionais (principalmente médicos) foi criada na cidade de São Paulo um "escolinha para crianças excepcionais", cuja mantenedora, a APAE de São Paulo, foi criada um ano e meio depois, no dia 8 de novembro de 1962 (FILHO, 1999, p.75).

Segundo Magalhães (apud BRASIL: 1991, p.45) no período de 1954 a 1962 foram criadas 16 (dezesseis) APAEs no Brasil. Devido à necessidade de intercambio de técnicas, troca de experiências, divulgação e padronização da terminologia e planejamento geral dos trabalhos, realizou-se no final de 1962, em São Paulo, a I ${ }^{a}$ Reunião Nacional de Dirigentes Apaenos, presidida pelo Dr. Stanislau Krysnsky. Participaram da reunião doze das dezesseis entidade existentes nas cidades de Caxias do Sul, Curitiba, Jundiaí, Muriaé, Natal, Porto Alegre, São Leopoldo, São Paulo, Londrina, Rio de Janeiro, Recife e Volta Redonda.

Em 1968, com o apoio do Exercito Brasileiro, a Sede da Federação Nacional das APAEs foi transferida para Brasília-DF. Por tratar-se de um pedido insistente do Movimento Apaeano, o então presidente da Federação Nacional das APAEs, cel José Cândido Mães Borba, entendeu que a mesma deveria estar localizada na capital do Brasil, visando, assim, facilitar as relações e inter-relações com os órgãos públicos e segmentos sociais em âmbito nacional (Federação Nacional das APAEs, 2001, p.24).

No Ceará, a Educação Especial teve seu início com a formação da Sociedade de Assistência aos Cegos, em 1942 e, em 1956 com a Sociedade Pestallozzi do Ceará, subvencionada de forma filantrópica.

O primeiro passo que o governo deu foi com a criação do Instituto Cearense de Educação de Surdo em 1961, seguido pela sociedade de Assistência aos Cegos, dispondo o Instituto de Cegos Dr. Helio Góes Ferreira de recursos humanos e materiais necessários ao desenvolvimento da Educação Especial.

Em 1972, com a criação do Serviço de Educação Especial, na Secretaria da Educação, iniciou-se a implantação de classes especiais nas escolas públicas para atender aos alunos com necessidades educativas especiais na rede estadual de ensino. 
Em cumprimento à lei 5.692/71 organizaram-se, em 1971, os setores de deficiência mental, física, auditiva e visual, no âmbito do Setor de Educação Especial da SEDUC (Secretaria de Educação Básica do Estado do Ceará).

Em 1975, o setor da Educação Especial passou a preparar recursos humanos especializados para a expansão do atendimento nas áreas de deficiências mental, auditiva e visual, sendo atendidos nas APAEs de todo o Brasil..

De 1976 a 1980 houve a elaboração da "proposta curricular" para D. M. com técnicas e materiais psicopedagógicos de iniciação para o trabalho, de artes nas oficinas pedagógicas.

De 1980 a 1990 realizou-se o I ${ }^{\circ}$ Curso de Formação de Professores de Estudos Adicionais na área de D. M. com recursos do CENESP (Centro Nacional de Educação Especial) do MEC (Ministério de Educação e Cultura). Nas reformas que aconteceram com a Secretaria da Educação, a Educação Especial desenvolveu processos de avanços, recebendo o mesmo nível de atenção das demais modalidades de ensino. No período de 1980 a 1990, o governo tentou ampliar e manter a qualidade do atendimento, dando aos professores cursos de capacitação para atender melhor os alunos com deficiências mais comprometidas.

Em 1996, implantou-se na estrutura organizacional do ensino fundamental da Secretaria da Educação Básica, através do decreto nº 24.226 de 23 de setembro de 1996 (D. O. de 27/09/1996) o Centro Integrado de Educação Especial, com ações especificas de atendimento ao alunado, enfatizando aspectos do seu desenvolvimento psicossocial, integração na família, na escola e na sociedade.

Com a promulgação da lei de Diretrizes e Bases da Educação Nacional - Lei ${ }^{\circ}$ 9394/96 o movimento de inclusão ganhou força. Está lei estabelece como objetivo de contribuir para a formulação de políticas para a Educação Especial no Ceará, foi realizado em agosto de 1997 uma reunião com educadores e estudantes no assunto, cujo tema foi "Fórum Estadual de Educação Especial e a nova LDB”. As principais recomendações decorrentes deste fórum foram:

- A inclusão das pessoas com necessidades educativas especiais no ensino regular;

- A formação e valorização do magistério especializado;

- Apoio às iniciativas das organizações não governamentais e parcerias com órgãos e instituições.

A LDB no 9394/96 define especial como a "modalidade de educação escolar oferecida preferencialmente na rede regular de ensino para educandos que apresentam necessidades especiais" com base no artigo 58 que estabelece: 
Haverá, quando necessário, serviços de apoio especializado, na escola regular para atender às peculiaridades da clientela da educação especial. $\mathrm{O}$ atendimento educacional será feito em classes, escolas ou serviços especializados, sempre que, em função das condições especificas dos alunos, não for possível a sua integração nas classes comuns de ensino regular.

Atualmente, a Educação Especial toma novos rumos, levando as pessoas com necessidades especiais a terem oportunidades de desenvolver as suas potencialidade buscando a sua cidadania, na escola e na sociedade.

No Ceará, segundo a técnica de educação especial da SEDUC, Lúcia Maria Gonçalves, em 2004, 9773 estudantes especiais foram incluídos na rede estadual, municipal e particular de ensino. Em 2005, este numero elevou-se para 10.438 matriculados (Diário do Nordeste, Fortaleza, 2005).

\section{A Educação Especial no Município do Crato-CE}

A história da Educação Especial no Crato teve inicio com a APAE (Associação de Pais e Amigos dos Excepcionais do Crato), em 06 de março de 1960 incorporando o Instituto de Reeducação Eveline Rolin Lucetti. Teve como primeira presidente a $\mathrm{Sr}^{\mathrm{a}}$ Francisca Luna Cruz, que administrou a APAE no período de 1969 a 1983.

Atualmente, a APAE dispõe de $2.400 \mathrm{~m}^{2}$ de área construída, assistindo em diversas modalidades de atendimentos a 129 alunos com necessidades especiais educativas especiais. Esta instituição atende as seguintes necessidades especiais: deficiência mental, sensorial, física e múltipla.

Mantém uma equipe multidisciplinar com atuação nas seguintes áreas: psicologia, fisioterapia, fonoaudialogia, serviço social, terapia ocupacional e pedagogia, estimulação precoce, psicomotricidade, música, teatro, coreografia, dramatização, culinária e laboratório de informática. Convém salientar que as orientações curriculares consistem na alfabetização e pós-alfabetização de jovens e adultos. 
$\mathrm{Na}$ oficina de música e teatro se trabalha literatura, poesias, emboladas, rimas, histórias e cantorias. Na arte visual: pintura e desenho. Na arte musical: dança moderna e dança folclórica.

No ensino regular o atendimento a pessoas portadoras de necessidades especiais ocorre de duas formas, a saber: classes especiais e presença nas salas de ensino regular. Classes especiais surgiram a partir de 1981 na Cidade do Crato. Os estabelecimentos de ensino pioneiros são a E. E. F. M. Estado da Bahia, E. E. F. Dom Quintino, Juvêncio Barreto, Presidente Vargas e Teodorico Teles, sendo que as duas últimas turmas já foram extintas.

As escolas de E. F. Dom Quintino e a E. E. F. M. Estado da Bahia já trabalhavam há mais de 20 anos com alunos especiais. Quando elas iniciaram, ainda não existia o nome inclusão e nem a luta pelo "direito a ter direito", que permitia a estes alunos acompanharem outra série, passando no ano seguinte para o ensino regular. Algumas vezes este aluno não era bem aceito, porque alguns professores achavam que os alunos com necessidades especiais iriam atrasar o conteúdo e que atrapalhariam os colegas.

\section{O Processo de Inclusão na opinião dos Professores}

A inclusão na cidade de Crato-Ce está acontecendo até certo ponto. Ainda falta maior sensibilização por parte das pessoas que trabalham com a educação. Não é só dizer que existem algumas pessoas com necessidades especiais nas escolas e oferecer capacitações, treinamentos para os professores; é preciso dar as condições físicas e materiais necessárias. Notamos ainda que há muita discriminação por parte de algumas escolas estaduais e particulares quando se trata do portador de necessidades especiais, principalmente em relação ao deficiente mental, por ser um aluno que requer mais atenção e um ensino mais diferenciado. O conteúdo é o mesmo, mas a maneira de como ensinar é que vai modificar para que estes alunos assimilem a matéria com mais facilidade.

São sete as escolas que já iniciaram a inclusão sem falar que a E. E. F. M. Estado da Bahia e a E. E. F. Dom Quintino, por terem classes especiais, já trabalham há mais tempo com a inclusão. Estas classes especiais trabalham com D. M. e todos os alunos que são aprovados passam para as escolas de ensino regular. Os que não são aprovados continuam na classe especial até que tenham condições de passar para as salas de ensino regular. 
Segundo as professoras destes estabelecimentos, dizem que apesar das limitações, eles acompanham os colegas e alguns são até mais interessados que os outros alunos. Quando estes educandos vão para as outras escolas, os professores de classes especiais sempre procuram saber o processo de aprendizagem de cada um. Contudo, existem casos de alunos que, por não acompanharem o ritmo de aprendizagem dos colegas e não encontram incentivos e apoio do professor, sentem-se desmotivados e desistem de estudar.

Optamos desde o início deste trabalho em não citar os nomes dos alunos e de professores para que não houvesse constrangimento, bem como para não comprometer a fidelidade das informações coletadas.

A partir do movimento de inclusão, o professor precisa ter capacidade de conviver com os diferentes, superando aos preconceitos em relação às minorias. Tem de estar sempre preparado para adaptar-se às novas situações que surgirão no interior da sala de aula (GODOFREDO: 1999, p.68).

O professor a partir do momento que recebe o aluno portador de necessidades especiais deve estar consciente que o mesmo tem suas limitações, devendo respeitá-lo e atendê-lo como manda a escola inclusiva, já que a educação é um direito de todos.

A professora da classe especial I da E. E. F. Dom Quintino comentou que a maior dificuldade que está sentindo é:

(...) como saber lidar como o aluno A, que não pára na carteira, não segue o ritmo da classe, distrai-se com muita facilidade, não presta atenção a uma explicação durante muito tempo, não termina as tarefas, bate nos colegas irritando-os, fazendo que os mesmos não brinquem com ele (...) É aí que nos falta uma pessoa que nos oriente, pois a mãe dá assistência, mas como a família é de baixa renda, não tem condições de levá-lo a um especialista. Quanto aos outros alunos, possuem problemas que a mão adquire durante a gestação como: desnutrição, maus tratos, má alimentação e muitas vezes tomam remédio para abortar.

Os alunos da classe especial II são mais adiantados, mas tem dois alunos bastante comprometidos com a aprendizagem. Ao entrevistar a professora da classe especial II da E. E. F. Dom Quintino, ela afirmou que: 
É uma turma comportada, mas tem certa dificuldade em aprender, principalmente dois alunos bastante comprometidos com a aprendizagem. Por falta de material didático, eu exploro suas memórias da melhor maneira possível. Faço com prazer, pois sempre gostei de ensinar aos alunos portadores de necessidades especiais.

A outra escola que faz parte da inclusão com D. M. é a E. E. F. M. Estado da Bahia, sendo que a professora é a mesma da classe especial II da E. E. F. Dom Quintino, ela argumenta que:

A diferença dos alunos desta escola para a outra é que estes alunos têm problemas com o comportamento, mas a aprendizagem já é melhor. Vêm de desajuste familiar como: pais biológicos viciados e mortos ainda jovens, educação dada por pais adotivos viciados e com problemas neurológicos, crianças abandonadas, outras bastantes doentes, vindas de grandes famílias pobres sem assistência familiar. Tem mãe que nunca foi à escola, mesmo recebendo aviso de reuniões de pais. Tenho também uma aluna como o mesmo comportamento do A da classe especial I da Escola Dom Quintino. Só que tive a ajuda da APAE e com o apoio da família ela passou por uma equipe de triagem e estamos esperando o resultado dos testes para sabermos como vamos nos orientar para que ela tenha uma boa aprendizagem e algumas limitações que a família terá que impor.

E continua:

Tenho um aluno com 18 anos que é diagnosticado como D. M. e já está cansado de freqüentar a classe especial, só que a mão não aceita sua deficiência e suas limitações, pois o mesmo não tem nem condições de ler, transmitir recados e fazer cálculos, entre outros problemas que a deficiência acarreta. Já foi para algumas escolas particulares e estaduais, mas estas não o aceitam, vejo que ele tem aptidão para a dança e a música, dei a idéia de colocá-lo na APAE, porque lá tem a banda APAGODE, tem dança e pintura que ele poderá gostar, mas a idéia na foi aceita. 
Conclui, dizendo:

Não temos ajuda de uma coordenação especial. Quem nos oferece todo o apoio, sem experiência de educação especial, é o núcleo gestor, com bastante boa vontade, procura nos ajudar, procurando saber o que é educação especial e abrindo portas para a escola inclusiva.

Vale ressaltar que de acordo com Taylor (1992, p.57), a depressão é classificada como distúrbio de humor, apresenta grande incidência e consiste em um dos males existentes nas sociedades contemporâneas. $\mathrm{O}$ autor vislumbra a magnitude de sua prevalência em ambos os sexos, em diversas faixas etárias e diferentes níveis socioeconômicos e acrescenta que na depressão, os sentimentos de tristeza e mágoa são prolongados ou exagerados além dos limites do razoável. Assim, deixa de ser um sintoma, tornando-se uma doença que envolve uma ampla diminuição das funções mentais e físicas.

Ainda sobre o processo de ensino e aprendizagem de alunos hiperativos a professora falou que:

No inicio fui uma professora exclusiva, pois não queria aceitá-los, nunca tinha lidado com um aluno hiperativo e não tinha ninguém para me orientar, mas fiquei, e digo da passagem, ficava com ele somente até as 15:00 horas e depois uma pessoa da casa dele vinha buscá-lo. Ele gritava muito, corria dentro da sala, batia e cuspia os colegas. Hoje eu consigo ficar com ele até o horário terminar. Soube que os irmãos não têm muita paciência de lidar com ele e a mãe por mais que se esforce não aceita que o filho é portador de necessidades especiais. Ele está melhor no que se refere ao comportamento com os colegas, já participa das festividades da escola, de passeios feitos pela sala de aula, já começa a melhorar na coordenação visomotora e fala melhor. Quando chegou na escola ninguém entendia o que ele dizia e a mãe não o colocou no fonoaudiólogo porque saía muito caro e não se interessou em saber se este tipo de atendimento era oferecido pelo SUS. Ao receber este aluno fiquei sem saber como ensiná-lo e me perguntava se ele assimilaria alguma coisa. 
Corrobora-se, através dos depoimentos expostos que ensinar existe alguns riscos e rejeição de qualquer forma de discriminação (FREIRE: 1999, p.39). O risco faz parte do desafio de se enfrentar o desconhecido. Ensinar, portanto, requer respeito, humildade, saber escutar, aceitar o diferente, sem discriminação. Principalmente o professor que ensina aos alunos com necessidades especiais.

Quando perguntamos à diretora como surgiu à idéia de trabalhar com alunos com necessidades especiais ela nos relatou que surgiu da necessidade de poder ajudar a integrar estas pessoas na escola regular e se possível na sociedade, pois a escola dispunha de espaço físico suficiente e professora especializada que trabalha na APAE, com deficientes auditivos.

Questionada sobre a aceitação dos D. A. na escola, disse-me que antes de acontecer à vinda deles da APAE para cá, tivemos o momento de sensibilização, como receberíamos estes alunos.

Ao ser interrogada sobre as dificuldades encontradas para que houvesse realmente uma inclusão, falou-me:

No momento está faltando tudo: material de trabalho, só possuímos propostas no papel. A prática de ação acontece precariamente, apenas com material humano... Faltam recursos específicos para que aconteça de fato e de direito.

Perguntamos sobre as dificuldades encontradas e se o CREDE 18 estava dando assistência, ela respondeu:

Encontramos as dificuldades nas condições físicas e materiais (aparelhos). O CREDE 18 nos dá assistência técnica com capacitações e treinamentos. Às vezes compramos material com o nosso próprio dinheiro.

Antes de finalizar a entrevista as educadoras relataram que a aula mais esperada durante a semana é a de informática, pois jogam, desenham e os mais adiantados fazem pequenas cópias.

Uma das 7 (sete) especialistas contratada pelo Estado, explica que "as línguas de sinais não são universais, cada país possui a sua. Os sinais são modificados de acordo com a região (Diário do Nordeste, Fortaleza, 2005). 
Outros questionamentos foram acerca das atividades desenvolvidas na sala de aula ou fora dela, ao que as professoras responderam:

Trabalhamos com figuras pra recorte e colagem, exploração de letras entre as palavras, palavras iniciadas com as consoantes e vogais, sempre associando a uma figura com a letra. Temos também aula de informática e com o uso do vídeo.

Com relação ao sistema de avaliação, responderam que:

A avaliação dos alunos é feita sempre de maneira continua e individualizada. É feita a comunicação através de sinais. Observamos a maneira de como se comunicam com os colegas. A avaliação propriamente dita acontece apenas para dar satisfação aos pais.

A professora de $1^{\mathrm{a}}$ a $4^{\mathrm{a}}$ série nos informou que,

As avaliações de Historia e Geografia são feitas com ajuda dos professores, por não terem a facilidade de assimilarem. Português e Matemática, há uma explica, para em seguida eles resolverem. A interpretação de textos é mais difícil por causa de algumas palavras.

Indagadas sobre a discriminação por parte dos outros alunos, uma das professoras falou: não houve discriminação por que os professores e o núcleo gestor foram nas salas conscientizando-os.

A outra professora nos informou que: no inicio houve discriminação por parte de alguns professores, pois achavam que os intérpretes iriam observá-los.

Sobre as dificuldades encontradas, uma professora falou: falta material para os trabalhos, como tinta guache, lápis, cartolina. Às vezes tiramos dinheiro do próprio bolso para comprarmos, outras vezes a escola e os pais nos dão.

A outra professora continua: sinto dificuldade no que diz respeito à língua portuguesa, pois em Libras eles conseguem se comunicar, mas na escrita têm dificuldade. 
Questionadas sobre os planejamentos, informaram que acontece aos sábados global (para todos os professores) e que, os planos individuais variam de acordo com as necessidades de cada um.

Entrevistou-se em seguida uma professora do ensino regular que recebe aluno com deficiência auditiva. Ela foi indagada sobre a inclusão no ensino regular, e nos afirmou que: está dando certo. O que falta ainda é mais assistência para haver melhor aprendizagem.

Em relação à metodologia, enfatizou: tem que ser diferenciada. Porque não sabem formular as palavras. E quanto às dificuldades: a comunicação, a falta de material e de uma capacitação para haver melhor aprendizagem.

Para apreciação do desempenho escolar dos alunos que estavam matriculados nas classes comuns, tomaram-se como indicadores os conceitos finais por eles obtidos nas áreas de ensino Língua Portuguesa, Matemática, Geografia, História, Ciências, Educação Artística e Educação Física, no ano letivo anterior, e sua freqüência, nesses respectivos anos.

\section{Conclusão}

Observou-se que ainda existe um certo preconceito por parte de alguns professores, principalmente devido à falta de conhecimento acerca das possibilidades e limitações das pessoas Portadoras de Necessidades Especiais. Mas é preciso reconhecer que atualmente há muitos professores que aceitam e comungam com a proposta da inclusão, aceitando o portador de necessidades especiais em condições de igualdade com outros alunos, mesmo ciente de suas condições neuro-psico-biológicas.

A falta de uma assistência permanente e multiprofissional de uma equipe de triagem (assistente social, psicólogo, fonoaudiólogo, terapeuta ocupacional, neurologista), que possa estar presente nas escolas, ainda é um desafio. Esta equipe tem a finalidade de diagnosticar o aluno, de forma a poder proceder o encaminhamento o ensino regular ou, se necessário, continuar na classe especial ou então ser encaminhado para outro tipo de atendimento.

Acreditamos que um trabalho junto ao professorado, de uma maneira geral, orientando-os sobre aspectos metodológicos do trabalho com Portadores de Necessidades Especiais, certamente contribuiria para uma melhoria do processo ensino-aprendizagem destes alunos. 
Quanto à família, a escola parece ter um papel fundamental junto a estes, de forma que sejam sensibilizados a aceitarem suas "diferenças" e ajudar no processo de desenvolvimento do portador de necessidades especial, de forma consciente e "produtiva".

\section{Referências}

BRASIL. Associação de Pais e Amigos dos Excepcionais. Histórico.Rio de Janeiro, 1991, p.43.

BRASIL. Federação Nacional da APAEs. APAE educadora. “A escola que buscamos”.

Proposta orientada das ações educacionais. Coordenação Geral: Ivonilde Maria Tibola

— Brasília-DF: MEC/SEF/SEESP, 2001, p.24.

BRASIL. Secretaria de Educação Fundamental. Parâmetros curriculares Nacionais: adaptações curriculares. Brasília: MEC/SEF/SEESP, 1999.

CARVALHO, R. E. O direito de ter direitos. Declaração de Salamanca de Princípios

Política e Prática para as Necessidades Educativas Especiais. In: Brasil - MEC, Secretaria de Educação a Distância/Salto para o futuro, Educação Especial: Tendências Atuais, Brasília; 1999, p.22-24.

Jornal Diário do Nordeste. A inclusão social. Fortaleza: agosto de 2005.

FILHO, Santos. O movimento apaeano: historia e evolução. Palestra proferida durante o

Curso de Formação de Multiplicadores na Área de Desenvolvimento Institucional e Gerencial - Projeto Águia (20/04/1999), São Paulo: Instituto APAE, 1999, p.75.

FREIRE, Paulo. Pedagogia da autonomia: saberes necessários à pratica educativa. $12^{\mathrm{a}}$ ed. São Paulo: Paz e Terra, 1999, p.57.

GLAT, Antonio. Inclusão total: mais uma utopia? Rio de Janeiro: Integração, 1997, p.28.

GLAT, Rosana. A Integração Social dos Portadores de Deficiências: Uma Reflexão. Coleção Questões Atuais em Educação Especial, Volume I, $2^{\circ}$ edição, Rio de Janeiro: Livraria Sete Letras Ltda, 1998.

GODOFREDO, V. L. Como formar professores para uma escola inclusiva?In Brasil MEC, Secretaria de Educação a Distância/Salto para o futuro, Educação Especial: Tendências Atuais, Brasília; 1999, p.68.

MANTOAN, Maria Teresa E. Ser ou estar: eis a questão - explicando o déficit 
intelectual. Rio de Janeiro: WVA, 1997.

REGO, Teresa Cristina. Vigotsky - Aprendizado e desenvolvimento, um processo histórico. São Paulo: Scipione, 1995, p.56.

SEDUC (Secretaria da Educação Básica do Ceará) - Política Estadual de Educação Especial. “Educação Especial - Marcas de um Caminho”. Serie: Educação Ceará: Fortaleza, 1995-1998, p.99.

TAYLOR, C. M. Fundamentos de enfermagem psiquiátrica. 13 ed. Porto Alegre. Artmed: 1992, p.57.

WERNECK, Cáudia. Ninguém mais vai ser bonzinho na sociedade inclusiva. Rio de Janeiro: WVA, 1997.

Sobre a autora:

(1) Vanessa Cinthya Bandeira Garcia é Especialista em Psicologia Aplicada à Educação pela Universidade Regional do Cariri - URCA.

E-mail: vanessacintiaband@hotmail.com

Como citar este artigo (Formato ISO):

GARCIA, V. C. B. . Reflexões sobre a Educação Especial no Município do Crato. Id on Line Revista de Psicologia, Novembro de 2009, vol.1, no.10, p.21-38. ISSN 1981-1189. 